\title{
Avaliação do Alcance Dinâmico de Imagens Digitalizadas - influência da resolução espacial e da modalidade de captura da Imagem
}

\author{
Radiologista (UFBA); Mestre em Odontologia - \\ área de concentração em Clínica Odontológica \\ (UFBA); Doutora em Odontologia (Concentração \\ Viviane Almeida Sarmento ${ }^{1}$ \\ em Estomatologia Clínica, PUCRS); Profa. Adjunta \\ da UFBA e da UFFS \\ (viviane.sarmento(a)terra.com.br). Endereço: Rua \\ Macaúbas 556, Rio Vermelho, 41.940-250 \\ Salvador-BA,.Brasil. Telefones: (71) 3248-5464 / \\ 9118-5054 \\ Cristina Bacellar de Pinho \\ Aluna do curso de Especialização em Ortodontia e \\ Ortopedia Facial da FOUFBA; ex-bolsista do \\ Programa Especial de Treinamento (PET). \\ Tipo de Análise do Manuscrito \\ Triple Blind Peer Review \\ Recebido em Nov/2009
}

\section{RESUMO}

A aparência de uma imagem radiográfica digitalizada é de extrema importância para uma correta interpretação e conseqüentemente, um efetivo diagnóstico. Objetivo: Sabendo-se que são vários os fatores que podem influenciar a qualidade de uma imagem digitalizada, variáveis aplicadas durante o processo de digitalização foram analisadas, a fim de eliminar possíveis interferências negativas. Metodologia: Os parâmetros avaliados incluíram a resolução espacial da imagem e a modalidade de captura. A repercussão dessas variáveis no alcance dinâmico de imagens digitalizadas foi analisada pelo programa Photoshop (Adobe Systems Incorporated, Mountain View, Califórnia, EUA). Resultados: Foi possível perceber que para as radiografias digitalizadas indiretamente, uma resolução espacial muito superior não é requerida. Conclusão: A proporção sinal/ruído (signal/noise ratio SNR) não deve ser negligenciada para as imagens digitais.

Palavras Chave: Imagem digital, Alcance dinâmico, Resolução espacial

${ }^{1}$ Agradeço à FOPUCRS, na pessoa da Profa Dra Nilza Pereira da Costa, por disponibilizar a utilização de vários equipamentos necessários à realização deste trabalho.

${ }^{2}$ Agradeço ao Prof. Jean Loup Coudert por permitir o acesso e uso dos equipamentos no Laboratoire d'Image, Signal et Acoustique (LISA) de l'École Supérieur de Chimie, Physique et Electronique (CPE) de l'Université Claude-Bernard (UCB), Lyon, France (Laboratório de Imagem, Sinal e A cústica da Escola Superior de Química, Física e Eletrônica da Universidade Claude-Bernard, Lyon, França) 


\title{
Evaluation of Dynamic Range Scanning Imaging - influence of spatial resolution and the type of image capture
}

\begin{abstract}
The appearance of a digital image is very important for a correct interpretation and, consequently, for a effective diagnosis. Purpose: There are many factors that may influence the quality of a digital image. The process of digitalization must be analyzed to make sure that possible negative interferences will be eliminated. Methods: Some of these interferences include image spatial resolution and image capture mode. Their repercussion in the dynamic range of digital images was analyzed by the program Photoshop (Adobe Systems Incorporated, Mountain View, California, USA). Results: The results showed that for a digitalized image, a spatial resolution much superior it is not required. Conclusion: For the digital images, the signal/noise ratio (SNR) cannot be neglected.
\end{abstract}

Keywords: Digital image, Dynamic range, Spatial resolution

\section{Evaluación de la gama dinámica de escaneo de imágenes - la influencia de la resolución espacial y el tipo de captura de imágenes}

\section{RESUIMEN}

La aparición de una imagen radiográfica digitalizada es extremadamente importante para la interpretación correcta y, por tanto, un diagnóstico eficaz. Objetivo: Teniendo en cuenta que hay varios factores que pueden influir en la calidad de una imagen escaneada, las variables aplicadas durante el proceso de digitalización se analizaron con el fin de eliminar posibles interferencias negativas. Métodos: Los parámetros evaluados fueron la resolución espacial y el modo de captura de imágenes. El impacto de estas variables en el rango dinámico de las imágenes digitalizadas se analizó el uso de Photoshop (Adobe Systems Incorporated, Mountain View, California, EE.UU.). Resultados: Fue posible comprender que las radiografías digitalizadas indirectamente, una resolución mucho mayor espacial no es necesario. Conclusión: La relación señal / ruido (relación señal / ruido - SNR) no debe ser descuidado para las imágenes digitales.

Palabras clave: digital de imagen, rango dinámico, la resolución espacial

\section{Évaluation de la Dynamic Range Imaging Scanning - influence de la résolution spatiale et le type de capture d'image}

\section{RÉSUMÉ}

L'apparition d'une image radiographique numérisée est extrêmement important pour l'interprétation correcte et donc, un diagnostic efficace. Objectif: Étant donné qu'il ya plusieurs facteurs qui peuvent influencer la qualité d'une image numérisée, les variables appliquées au cours du processus de numérisation ont été analysés afin d'éliminer les possibles interférences négatives. Méthodes: Les paramètres évalués comprenaient la résolution spatiale et le mode de capture d'image. L'impact de ces variables dans la plage dynamique des images numérisées ont été analysées en utilisant Photoshop (Adobe Systems Incorporated, Mountain View, Californie, USA). Résultats: Il était possible de réaliser que les radiographies numérisées indirectement, une résolution spatiale beaucoup plus élevée n'est pas nécessaire. Conclusion: Le rapport signal / bruit (rapport signal / bruit - SNR) ne doit pas être négligé pour les images numériques.

Mots-clés: imagerie numérique, la plage dynamique, résolution spatiale 


\section{Introdução}

Para obter uma imagem digitalizada, pode-se recorrer a métodos diretos ou indiretos. Os primeiros permitem a obtenção de imagens por intermédio de sensores ou placas de captura à base de fósforo, que substituem os filmes radiográficos. Já os métodos indiretos utilizam principalmente scanners com leitores de transparência, que digitalizam radiografias obtidas pelos meios convencionais. A forma de capturar essas imagens irá repercutir diretamente na sua resolução espacial e no seu alcance dinâmico, que pode ser definido com a quantidade de tons de cinza que uma imagem pode exibir. Estas características físicas estão relacionadas com a qualidade da imagem para interpretação.

Desde 1987, quando o primeiro sistema para digitalização de imagens radiográficas intrabucais foi lançado no mercado, inúmeros trabalhos têm sido realizados e publicados, com o objetivo de avaliar o desempenho desses sistemas. Entre os critérios estudados, destacam-se a qualidade da imagem para diagnóstico, as formas de aquisição da imagem, as possibilidades de manipulação, as análises automatizadas e as aplicações dos programas (1).

O alcance dinâmico é um fator de extrema importância quando se deseja analisar uma imagem radiográfica, pois um maior alcance dinâmico parece melhorar a interpretação (2-4). Sabe-se que a amplitude da escala de cinza de uma imagem digitalizada indiretamente por scanners ordinários é inferior à escala da radiografia original (5). Além disso, a aquisição direta amplia a dinâmica das imagens, principalmente devido a uma correção automática de brilho e contraste desses programas, que procuram determinar uma melhor distribuição dos níveis de cinza (1).

Em relação à resolução espacial de imagens digitalizadas, Ohki et al. (5) afirmaram que imagens com pixels maiores que $100 \square \mathrm{m}$ perdem sua acurácia para diagnóstico. Não é comumente relatada, no entanto, a relação da extensão da escala de cinza com a resolução espacial de imagens digitais. Este trabalho teve como objetivo testar o alcance dinâmico ou amplitude da escala de cinza de imagens digitais e de radiografias digitalizadas, em relação aos fatores resolução espacial e modalidade de captura da imagem.

\section{Material \& Método}

\section{Obtenção e processamento das imagens}

Foram radiografadas mandíbulas de vinte ratos, sobre filmes radiográficos convencionais do tipo periapical, tamanho 2 , de velocidade $\mathrm{D}$, todos do mesmo lote de fabricação e também sobre placas de captura à base de fósforo do sistema Digora (Soredex, Orion Corporation, Helsinki, Finlândia). A distância focal foi de $30 \mathrm{~cm}$. O tempo de exposição, escolhido no teste-piloto, foi de $0,5 "$, para as radiografias convencionais, e de $0,2 "$ para as imagens digitais. As radiografias convencionais foram processadas automaticamente. As imagens obtidas sobre as placas de captura foram processadas na unidade de leitura que acompanha o sistema Digora. As características da imagem diretamente digitalizada, em relação a brilho e contraste, foram automaticamente ajustadas pelo programa do sistema Digora.

\section{Preparação das imagens}

As radiografias convencionais foram capturadas por dois diferentes scanners a laser, com leitor de transparência. No primeiro equipamento as radiografias convencionais foram digitalizadas com uma resolução espacial de 75 dpi (pixel de $340 \square \mathrm{m}$ ), 8 bits, no 
modo foto preto e branco, no formato BMP, com tamanho de $400 \%$ do seu tamanho original e arquivadas em disquetes $3^{1 / 2}$ ". Cada primeira imagem teve seu brilho e contraste ajustados automaticamente pelo programa de captura e esses valores foram mantidos para as demais, quando da sua digitalização. No segundo equipamento as radiografias convencionais foram digitalizadas com uma resolução espacial de 1200 dpi (pixel de 21 $\square \mathrm{m}$ ), 8 bits, no modo foto preto e branco, no formato BMP, com tamanho de $1600 \%$ do original e arquivadas em CD-ROM. Desta vez as radiografias foram digitalizadas em dois grupos de dez imagens, fazendo com que houvesse uma menor variabilidade da fonte de laser durante a captura. Entre esses dois grupos, os níveis de brilho e contraste foram padronizados.

As imagens digitais obtidas pelo sistema Digora foram inicialmente arquivadas nas fichas do programa, sem que qualquer alteração fosse realizada pelo operador na sua aparência. Cada pixel possuía $70 \times 70 \square \mathrm{m}, 8$ bits e $234 \mathrm{~Kb}$, segundo o fabricante. Essas imagens foram exportadas, no formato BMP, com uma resolução de 72 dpi (pixels de 353 $\square \mathrm{m}$ ) e 8 bits. As imagens foram então armazenadas em disquetes $3^{1 / 2}$.

\section{Análise das imagens}

O nível mais claro e o mais escuro do histograma de cada imagem foram mensurados pelo programa Photoshop 5.5 (Adobe Systems Incorporated, Mountain View, Califórnia, EUA), e o alcance dinâmico foi calculado pela diferença entre esses dois valores. Esses dados foram comparados, em relação às variáveis: resolução espacial $(72,75$ ou 1200 dpi) e modalidade de captura (digitalização direta ou indireta). Durante a anotação dos valores do histograma de cada imagem, essas foram exibidas em $100 \%$ do seu tamanho de captura e os examinadores não puderam realizar qualquer alteração na sua aparência. Foi empregado o teste $t$ de Student para amostras pareadas, para um nível de significância de $5 \%$.

\section{Resultados}

A metodologia aplicada permitiu a obtenção dos resultados apresentados. Comparando-se as imagens digitalizadas indiretamente com diferentes resoluções espaciais (75 e 1200 dpi), em relação ao seu alcance dinâmico, pode-se constatar os resultados mostrados na figura 1.

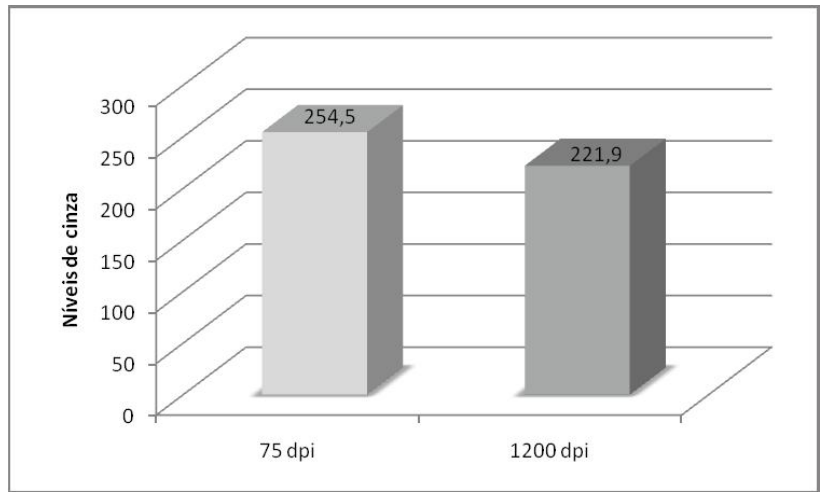

Figura 1. Média do número de níveis de cinza exibidos em cada imagem $(0,5 " \mathrm{e}$ captura indireta), a depender de sua resolução espacial. 
Nessa comparação, as variáveis tempo de exposição e modalidade de captura mantiveram-se constantes, enquanto a resolução espacial da imagem variou. Foi possível observar que as imagens com uma melhor resolução espacial (1200 dpi) mostraram um menor alcance dinâmico. Essa diferença foi estatisticamente significante $(p<0,001)$. Já quando se comparou as imagens digitais (0,2", 72 dpi) com aquelas indiretamente digitalizadas (0,5", 1200 dpi), em relação às suas resoluções espaciais e amplitude da escala de cinza, observou-se também que as últimas, com resolução espacial superior, tiveram uma menor escala de cinza $(p=0,007)$ (figura 2$)$.

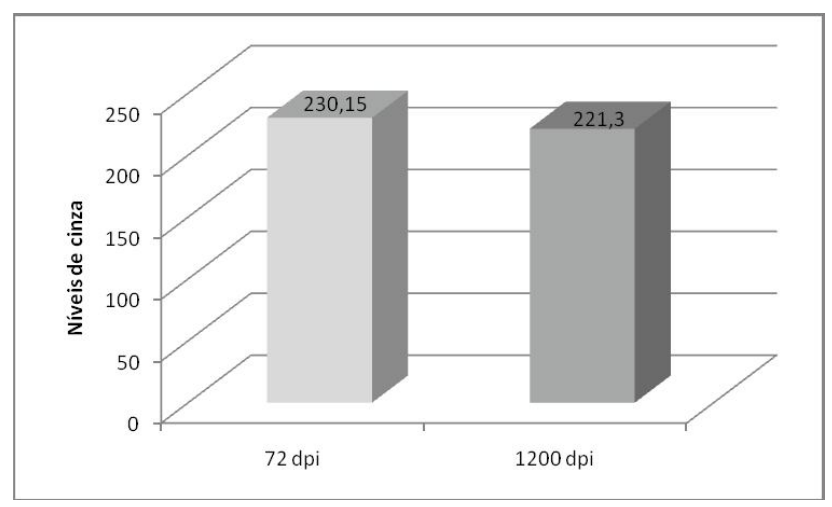

Figura 2: Média do número de níveis de cinza exibidos em cada imagem (o,2" e o,5"; captura direta e indireta, respectivamente), a depender de sua resolução espacial.

Porém, ao se comparar o alcance dinâmico de imagens com resoluções espaciais de 72 e 75 dpi, e capturadas por métodos distintos (direto e indireto, respectivamente) e com tempos de exposição diferentes (0,2"e $\left.0,5^{\prime \prime}\right)$ observou-se os resultados que são mostrados na figura 3. Neste caso, notou-se que as imagens de 75 dpi tiveram uma maior amplitude da escala de cinza do que as imagens digitais, de 72 dpi. Essas diferenças foram significativas $(\mathrm{p}<0,001)$.

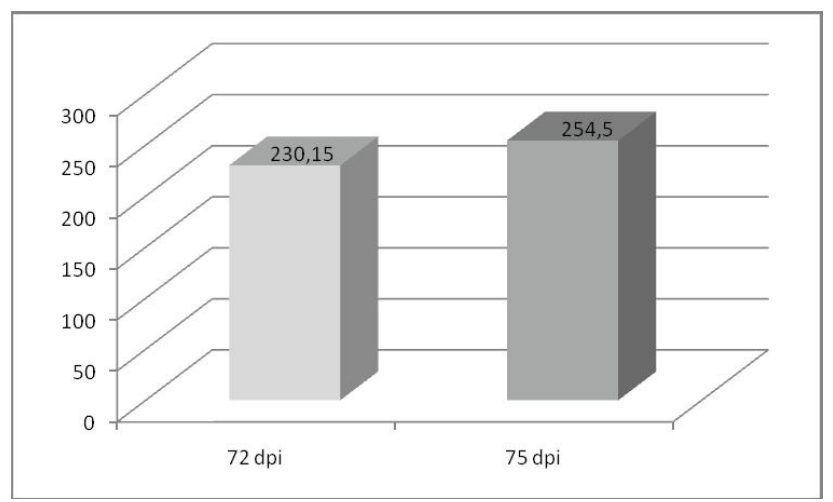

Figura 3: Média do número de níveis de cinza exibidos em cada imagem (72 e 75 dpi), a depender do modo de captura (direto e indireto, respectivamente). 


\section{Discussão}

É necessário destacar que a alteração de qualquer dos fatores físicos relacionados ao processo de digitalização (aquisição, processamento, exibição e armazenamento) pode ter repercussão em algum outro, o que torna a presente análise mais complexa. Por exemplo, sabe-se que a modalidade de captura modula o tempo de exposição utilizado, pois quando a imagem digital é adquirida, um menor tempo de exposição é exigido devido à sensibilidade dos receptores de imagem dos sistemas digitais, em relação ao tempo de exposição utilizado nas radiografias convencionais (1). A placa de captura à base de fósforo ainda requer um menor tempo de exposição do que os sistemas baseados no uso de CCD (Charge Coupled Device - dispositivo acoplado de carga) (6).

$\mathrm{Na}$ comparação das imagens digitalizadas indiretamente, nas quais a variação foi apenas a resolução espacial (75 e 1200 dpi), em relação ao seu alcance dinâmico, é preciso ressaltar que embora ambas as imagens tenham sido capturadas por scanners, os equipamentos foram diferentes (HP, ScanJet 6100C/T; Agfa, Duoscan T 1200). Mesmo que se tenha tentado padronizar o brilho e contraste dessa captura, os algoritmos desses equipamentos podem ser distintos, o que determinaria diferenças na exibição dos seus níveis de cinza. Isso pode ter repercutido, pelo menos em parte, nos resultados.

Embora se acredite que melhores resoluções espaciais e mais extensos alcances dinâmicos melhorem a qualidade de imagens digitalizadas, no presente trabalho, como pode ser observado na figura 1, uma melhor resolução espacial (1200 dpi) não significou um melhor alcance dinâmico. Sabe-se que a maioria dos scanners atualmente disponíveis no mercado oferecem resoluções espaciais de $300 \times 600$ ou $600 \times 1200 \mathrm{dpi}$, sendo que o valor mais baixo é o que realmente indica a resolução ótica do equipamento. Assim, resoluções maiores que 300 ou 600 , obtidas respectivamente por aqueles aparelhos são resultado de interpolações (7).

Interpolar significa calcular ou estimar valores intermediários a partir de valores conhecidos. Em imagens interpoladas não existe qualquer informação adicional em relação à imagem original. A imagem é apenas maior porque as informações são repetidas algumas vezes (7).

Quando uma imagem é capturada com uma resolução espacial maior que 300 ou 600 dpi, a depender do equipamento, novos pixels são criados. Quando ela é reduzida, pixels são eliminados. Sabe-se que esses processos podem utilizar diferentes fórmulas matemáticas para criar novos pixels. Esses métodos incluem a interpolação na ordem zero ou "vizinho mais próximo", a interpolação bilinear e a convolução cúbica. No primeiro método, a intensidade dos novos pixels é oriunda da duplicação, triplicação, e assim por diante, dos pixels existentes. Pelos outros dois métodos, fórmulas matemáticas foram elaboradas para que a intensidade de cinza do novo pixel provenha da interpolação de quatro (interpolação bilinear) ou dezesseis (convolução cúbica) pixels vizinhos (1).

Para imagens capturas com escala de cinza, as interpolações não são úteis e na verdade até pioram a qualidade da imagem (7). O presente trabalho comprova que imagens radiográficas obtidas com 1200 dpi realmente não são melhores que aquelas de 75 dpi, já que as primeiras apresentaram um menor alcance dinâmico, apesar de possuírem uma maior resolução espacial. Além disso, imagens muito grandes, como as de 1200 dpi, requerem um maior espaço para seu armazenamento (5).

$\mathrm{O}$ mesmo fato se repetiu entre imagens capturadas por modalidades diferentes (direta e indireta) e com resoluções espaciais distintas (72 e $1200 \mathrm{dpi}$, respectivamente). Assim, quando os equipamentos utilizados para capturar as imagens são diferentes (um sistema digital e um scanner), as fórmulas matemáticas por eles empregadas talvez tenham 
determinado os resultados observados na figura 2, na qual o alcance dinâmico das imagens de 72 dpi foi maior do que daquelas de 1200 dpi.

$\mathrm{Na}$ análise das imagens com resolução espacial semelhante (72 e 75 dpi), porém capturadas por métodos diferentes - direto e indireto - pode-se observar que as imagens digitalizadas exibiram uma escala de cinza mais longa, do que as imagens digitais, indo de encontro às afirmações de Versteeg et al. (1). Para explicar isso, é preciso compreender que quando uma imagem digital (sem a utilização de filme radiográfico) é adquirida, é necessário determinar o tempo de exposição ótimo para uma imagem de melhor qualidade, pois as superfícies de registro desses sistemas são mais sensíveis que os filmes convencionais. A exposição aos raios $\mathrm{X}$ nos sistemas digitais está fortemente relacionada com o ruído da imagem, que é a flutuação indesejável na intensidade dos pixels (8). A maior causa de ruído é a própria heterogeneidade do fóton de raios $(\mathbf{1}, 9)$. Por isso, quanto menor o tempo de exposição utilizado, mais ruído pode ser percebido e isso pode produzir um efeito negativo, se o sinal for menor que o ruído (10). Além disso, o ruído é mais evidente nas imagens exibidas no vídeo, devido ao tamanho sob o qual elas são visualizadas $(9,11)$. Quando o tempo de exposição mínimo requerido é ultrapassado, quanto maior o tempo de exposição, maior será o ruído, principalmente pela incorporação de dark current. Este, por sua vez, está diretamente relacionado com a temperatura dos dispositivos eletrônicos do sensor, provocando uma maior deposição de carga elétrica e escurecimento adicional da imagem que, no entanto, é desprezível (11). Já um tempo de exposição muito grande poderá saturar todos os pixels da área e ainda determinar o espalhamento de elétrons criados naquelas áreas para as áreas vizinhas, determinando o escurecimento total ou parcial da imagem (blooming), prejudicando sua aparência, às vezes de forma irreversível (11). O sistema Digora recomenda que o tempo de exposição ideal seja aquele que se situa entre 10 e 100\% do máximo calibrado para aquele sistema, já que assim o ajuste automático da escala de cinza determinará a exibição de uma imagem de adequado contraste $(12,13)$. Esse aspecto não foi observado quando da obtenção das imagens pelo sistema Digora e, portanto, não se pode afirmar que o tempo de 0,2 " empregado foi o ideal. Sob um aspecto subjetivo, essas imagens pareciam pouco densas, talvez como resultado de um tempo de exposição inadequado, que reduz o SNR (signal/noise ratio - proporção sinal/ruído). Nessas situações, o alcance dinâmico deverá se deteriorar (11). Na presente pesquisa, é possível sugerir que a menor amplitude da escala de cinza das imagens digitais (o,2", $72 \mathrm{dpi})$, em relação àquelas digitalizadas indiretamente $(0,5 ", 75$ dpi) é resultado principalmente do seu pobre SNR, motivado por um inadequado tempo de exposição que comprometeu o ajuste automático da escala de cinza pelo sistema. Quando o sistema é calibrado e um tempo de exposição adequado é empregado, o ajuste automático do sistema Digora regula a imagem, conservando os cento e vinte valores centrais de seu histograma e convertendo os demais em zero ou em duzentos e cinqüienta e cinco, o que alonga a escala de cinza e aumenta seu contraste (14). Em condições ótimas, esse ajuste automático da escala de cinza de alguns sistemas diretos deve tornar essas imagens superiores às imagens de radiografais convencionais que são digitalizadas indiretamente, em relação ao seu alcance dinâmico. Caso contrário o ruído pode interferir na intensidade dos pixels e diminuir o alcance dinâmico das imagens digitais.

Deve-se ressaltar que mesmo que um incorreto tempo de exposição tenha sido empregado, as imagens digitais ainda tiveram um maior alcance dinâmico que as imagens de 1200 dpi. Recomenda-se então que nas imagens digitais obtidas pelo sistema Digora, o tempo de exposição mais adequado deve situar-se entre 10 a 100\% do máximo calibrado, de forma a aumentar a SNR. Se uma melhor SNR puder ser obtida, imagens digitais devem ser preferidas àquelas digitalizadas indiretamente, uma vez que aquela modalidade de 
captura emprega menores tempos de exposição, dispensa a fase de processamento em câmara escura, fonte de grandes variações na escala de cinza da radiografia final e provavelmente oferece uma imagem com um contraste satisfatório.

Com base nesses resultados, é lícito afirmar que quando se trabalha com imagens digitais é preciso determinar que variável, resolução espacial ou alcance dinâmico, será otimizada. Khademi (2) afirmou que a interpretação é basicamente um processo de discriminar contrastes, e então capturar uma radiografia com uma resolução espacial suficiente para diagnóstico não é difícil, o problema é captar todos os níveis de cinza de uma imagem radiográfica.

É difícil determinar, no entanto, o quanto pequenas diferenças em tamanho de escala de cinza podem repercutir na acurácia do diagnóstico. Neste estudo a influência do alcance dinâmico na interpretação das imagens não foi analisada.

\section{Conclusão}

Para imagens digitalizadas indiretamente:

- Uma resolução espacial muito grande parece diminuir o alcance dinâmico, além de requerer muito espaço para armazenamento.

Para imagens obtidas por sistema digitais diretos:

- O tempo de exposição deve ser calculado a depender do tempo máximo calibrado para o sistema, de modo a aumentar a SNR e permitir que o controle automático do programa exiba uma imagem com contraste adequado.

\section{Referências}

1. Versteeg CH, Sanderink GCH, Van Der Stelt PF. Efficacy of digital intra-oral radiography in clinical dentistry. J Dent 1997;25:215-224.

2. Khademi JA. Digital images \& sound. J Dent Educ 1996; 60:41-6.

3. Sarmento VA. Diagnóstico radiográfico de alterações periapicais de origem endodôntica através da determinação do nível de cinza em imagens digitalizadas - estudo experimental em ratos [Tese]. Porto Alegre (RS): Faculdade de Odontologia, Pontifícia Universidade Católica do Rio Grande do Sul; 2000.

4. Sarmento VA, Pretto SM, Costa NP. Entendendo a imagem digitalizada. Rev Odonto Ciência 1999;14:171-8.

5. Ohki M, Okano T, Nakamura T. Factors determining the diagnostic accuracy of digitized convencional intraoral radiographs. Dentomaxillofac Radiol 1994;23:77-82.

6. Borg E, Gröndahl K, Gröndahl HG. Marginal bone level buccal to mandibular molars in digital radiographs from charge-coupled device and storage phosphor systems. An in vitro study. J Clin Periodontol 1997;24:306-12.

7. Fulton W. A few scanning tips [online? Disponível em www.scantips.com. [Acesso em 20 de maio de 2001].

8. Shrout MK, Potter BJ, Yurgalavage HM, Hildebolt CF, Vannier MW. 35-mm film scanner as an intraoral dental radiograph digitizer. I: a quantitative evaluation. Oral Surg Oral Med Oral Pathol Oral Radiol Endod 1993;76:502-9.

9. Welander U, Nelvig P, Tronje G, McDavid WD, Dove SB, Mörner AC, et al. Basic technical properties of a system for direct acquisition of digital intraoral radiographs. Oral Surg Oral Med Oral Pathol Oral Radiol Endod 1993;75:506-16. 
10. Wenzel A. Sensor noise in direct digital imaging (the RadioVisioGraphy, Sens-A-Ray, and Visualix/Vixa systems) evaluated by subtration radiography. Oral Surg Oral Med Oral Pathol Oral Radiol Endod 1994:77:70-4.

11. Molteni R. Direct digital dental x-ray imaging with Visualix/VIXA. Oral Surg Oral Med Oral Pathol Oral Radiol Endod 1993;76:235-43.

12. Hayakawa Y, Farman AG, Kelly MS, Kuroyanagi K. Intraoral radiographic storage phosphor image mean pixel values and signal-to-noise ratio. Oral Surg Oral Med Oral Pathol Oral Radiol Endod 1998;86:601-5.

13. Soredex Orion Corporation. Digora - installation, setup, and user's guide. Helsinki, 1995.

14. Velders XL, Sanderink GCH, Van Der Stelt PF. Dose reduction of two digital sensor systems measuring file lengths. Oral Surg Oral Med Oral Pathol Oral Radiol Endod 1996;81:607-12. 